\title{
Analisis Kepuasan Terhadap Green Transportation
}

\author{
Salvina*, Akbar Rizki*, Indahwati*, \\ ${ }^{*}$ Departemen Statistika Institut Pertanian Bogor
}

\begin{abstract}
Abstrak-One of the stages of the Green Campus 2020 program as an effort of IPB towards World Class University (WCU) is to carry out the Green Transportation (GT) movement. Buses, electric cars, bicycles, and electric motorcycle taxis are the GT transportation modes in IPB. The purpose of this study was to determine the level of satisfaction of GT users and identify attributes that are important and need to be improved so that the GT service system can be improved. This study uses survey data conducted by researchers on undergraduate students who use GT transportation mode in the past week. The sampling method used is random layered sampling with layers in the form of faculties. The analytical methods used are Importance Performance Analysis (IPA), Customer Satisfaction Index (CSI), biplot analysis, and simple correspondence analysis. The CSI value obtained is 2.96 (1-4 scale) with a CSI percentage of 74
\end{abstract}

Kata kunci-biplot; green transportation; IPACSI;korespondensi sederhana;

\section{PENDAHULUAN}

\section{A. Latar Belakang}

Salah satu upaya yang dilakukan Institut Pertanian Bogor (IPB) untuk menuju WCU adalah dengan mewujudkan Green Campus 2020. Gerakan Green Transportation (GT) adalah salah satu tahapannya. Hal ini sesuai dengan surat Keputusan Rektor IPB Nomor 205/IT3/LK/2015 tentang pelaksanaan Green Campus 2020 di lingkungan IPB. Gerakan GT tersebut mendorong penggunaan sepeda, mobil listrik, dan bus serta membebaskan ruas jalan tertentu dari sepeda motor dan mobil untuk mengurangi penggunaan bahan bakar minyak di dalam Kampus IPB, Dramaga. IPB berkomitmen untuk meningkatkan efisiensi energi dan kualitas lingkungan belajar yang sehat dan kondusif. Komitmen tersebut tidak hanya demi kepentingan mahasiswanya, tetapi juga diharapkan dapat berdampak baik bagi lingkungan sek- itar. Green Transportation adalah sistem transportasi ramah lingkungan yang mendorong penggunaan kendaraan transportasi kampus seperti mobil listrik dan bus. Rute jalan di wilayah Kampus IPB dibagi menjadi 5 (lima) koridor dengan pembagian jalan yang menyesuaikan tujuan pengguna.

Penerapan kebijakan GT di IPB diharapkan mendorong civitas akademika untuk beralih mode transportasi dengan menggunakan bus, sepeda, ataupun berjalan kaki dalam beraktivitas di lingkungan kampus. Hal ini diharapkan dapat mengurangi penggunaan kendaraan bermotor pribadi dan mengurangi penggunaan ojek kampus di lingkungan kampus IPB. IPB telah melakukan beberapa penataan transportasi guna mendukung program ini, seperti mendorong penggunaan sepeda, penambahan jumlah sepeda dan shelter sepeda, pengembangan pedestrian road, pengembangan transportasi massal, serta penataan parkir. Pengukuran terhadap perbaikan layanan ini sangat diperlukan untuk mengukur kinerja dari kebijakan GT tersebut. Oleh karena itu perlu dilakukan survei untuk mengukur kualitas layanan sistem GT di IPB agar mewujudkanGreen Campus 2020.

Responden yang menjadi target survei adalah mahasiswa tingkat sarjana yang menggunakan mode transportasi GT dalam seminggu terakhir. Teknik penarikan contoh yang digunakan adalah penarikan contoh acak berlapis (PCAB) dengan lapisan berupa fakultas. Hal ini dikarenakan IPB memiliki wilayah yang luas dan lokasi fakultas sebagai mayoritas tempat perkuliahan dengan rute mode transportasi GT yang berbeda-beda. Metode analisis yang akan digunakan pada penelitian ini adalah Importance Performance Analysis (IPA), Customer Satisfaction Index (CSI), analisis biplot dan analisis korespondensi. Metode IPA digu- 
nakan untuk mengukur kepuasan pelanggan dengan mempertimbangkan tingkat kepentingan dan tingkat kinerja pelayanan. Analisis CSI digunakan untuk mengukur tingkat kepuasan pengguna dengan pembobotan dari kepentingan unit pelayanan. Analisis biplot digunakan untuk melihat karakteristik pengguna GT dengan atribut 5 aspek yang dinilai pada layanan GT. Analisis korespondensi digunakan untuk melihat profil hubungan antara strata (fakultas) dengan kecenderungan jenis GT. Hasil penelitian diharapkan dapat digunakan untuk memperbaiki pelayanan sistem GT di IPB.

\section{B. Tujuan}

Tujuan dilakukannya penelitian ini adalah :

1) Mengukur tingkat kepuasan pengguna GT terhadap layanan sistem GT.

2) Mengidentifikasi atribut-atribut layanan sistem GT yang perlu ditingkatkan dan dipertahankan dalam memenuhi kepuasan pengguna GT.

3) Mengidentifikasi karakteristik pengguna GT dengan kecenderungan jenis GT yang dipilih

\section{METODOLOGI}

\section{A. Data}

Data yang digunakan dalam penelitian ini adalah data primer hasil survei peneliti. Alat yang digunakan pengumpulan data adalah kuesioner. Survei dilakukan dengan online dan offline. Survei dilakukan pada tanggal 20 April- 2 juni 2018. Responden dari penelitian ini adalah mahasiswa IPB program sarjana yang menggunakan mode transportasi GT. Metode pengumpulan data dengan memberi pertanyaan atau pernyataan yang sesuai dengan topik penelitian kepada responden. Ada tiga jenis pertanyaan dalam kuesioner yaitu tertutup, terbuka, dan campuran.

\section{B. Prosedur Pengambilan Data}

Tahapan-tahapan pengambilan data pada penelitian ini adalah sebagai berikut:

1) Merancang kuesioner
2) Survei pendahuluan.

Salah satu tujuan dilaksanakannya survei pendahuluan adalah untuk menguji validitas dan reabilitas kuesioner. Sebelum kuesioner digunakan pada proses survei. Kuesioner dikatakan valid jika kuesioner mampu mengukur apa yang ingin diukur (Sevilla (1998)).

Uji reliabilitas bertujuan untuk menunjukkan sejauh mana kekonsistenan kuesioner. Kuesioner dikatakan konsisten bila memberikan hasil yang sama ketika kuesioner dicobakan berulang-ulang. Salah satu cara menguji kekonsistenan kuesioner yaitu menggunakan uji Cronbach alpha (Siregar (2013)). Uji validitas pada penelitian ini dilakukan menggunakan korelasi bivariat pearson sedangkan uji reliabilitas dilakukan dengan uji cronbach alpha.

3) Penarikan contoh.

Metode penarikan contoh yang digunakan pada penelitian ini adalah penarikan contoh acak berlapis (PCAB). Scheaffer et al. (2012) menyatakan bahwa Penarikan contoh acak berlapis merupakan salah satu teknik penarikan contoh berpeluang yang dilakukan dengan cara membagi elemen populasi ke dalam kelompok yang tidak saling tumpang tindih, yang disebut strata. Penentuan contoh dilakukan secara acak dari masing-masing strata. Strata yang digunakan adalah fakultas, dimana pemilihan fakultas dipilih berdasarkan pertimbangan rute jalan wilayah yang dilewati mode transportasi tersebut. Ukuran contoh dilakukan dengan menggunakan ukuran contoh menduga proporsi dengan batas kesalahan 5\%. Ukuran contoh dan populasi pada setiap lapisan disajikan pada tabel 1

4) Survei responden.

Pengisian kuesioner dilakukan secara online dan offline oleh responden yang telah ditentukan secara acak sebelumnya. 
Tabel I

KATEGORI NILAIJumlah ukuran populasi dan ukuran contoh setiap lapisan

\begin{tabular}{lcc}
\hline \multicolumn{1}{c}{ Nama Fakultas } & $\begin{array}{c}\text { Ukuran populasi } \\
\text { mahasiswa }\end{array}$ & $\begin{array}{c}\text { Ukuran contoh } \\
\text { yang diambil }\end{array}$ \\
\hline Pertanian (FAPERTA/A) & 1248 & 34 \\
Kedokteran Hewan (FKH/B) & 508 & 14 \\
Perikanan dan Ilmu Kelautan (FPIK/C) & 1313 & 36 \\
Peternakan (FAPET/D) & 624 & 17 \\
Kehutanan (FAHUTAN/E) & 1101 & 30 \\
Teknologi Pertanian (FATETA/F) & 1200 & 33 \\
Matematika dan Ilmu Pengetahuan & 1945 & 54 \\
Alam (FMIPA/G) & & 40 \\
Ekonomi dan Manajemen (FEM/H) & 1445 & 26 \\
Ekologi Manusia (FEMA/I) & 933 & 105 \\
Program Pendidikan Kompetensi & 3819 & \\
Umum (PPKU) & & \\
\hline
\end{tabular}

\section{Prosedur Analisis Data}

Tahapan-tahapan analisis data pada penelitian ini adalah sebagai berikut:

a) Analisis statistika deskriptif. Analisis deskriptif dilakukan mengeksplorasi dan menyajikan informasi yang diperoleh. Penyajian informasi tersebut bisa dalam bentuk diagram ataupun tabel. Hasil yang diperoleh pada analisis ini memberikan gambaran awal bagaimana karakteristik pengguna GT.

b) Analisis IPA-CSI.

Analisis Customer Satisfaction Index(CSI) bertujuan untuk mengukur tingkat kepuasan pengguna GT. Analisis CSI dapat menghasilkan indeks yang menggambarkan tingkat kepuasan mahasiswa menggunakan mode transportasi GT. Langkahlangkah untuk melakukan analisis CSI adalah :

i) Mengukur tingkat kepentingan dan tingkat kepuasan mahasiswa dari setiap item yang mempengaruhi kepuasan mahasiswa terhadap GT dengan skala 1-4.

ii) Menghitung importance weighting factor dari skor masing-masing item dibagi total kepentingan seluruh item.

iii) Weighted score diperoleh dari perkalian importance weighting factor dengan skor kepuasan masing-masing item.

iv) Weighted averagediperoleh dari penjumlahan weighted score seluruh item.

v) CSI diperoleh dari pembagian weighted average dengan skala maksimum yang digunakan.

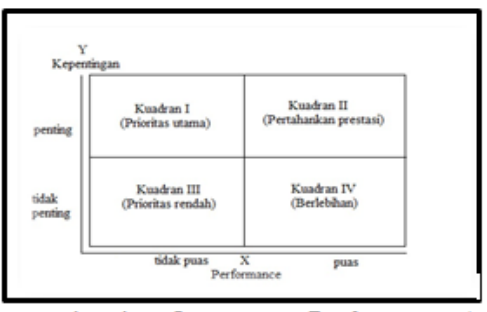

Gambar 1 Diagram kuadran Importance Performance Analysis.

Gambar 1. Diagram kuadran Importance Performance Analysis

Metode Importance Performance Analysis (IPA) kemudian digunakan untuk mengidentifikasi atribut-atribut layanan GT. Hal ini perlu dilakukan untuk mengetahui atribut yang perlu ditingkatkan atau dipertahankan. Diagram IPA seperti terlihat pada Gambar 1. Memperlihatkan tingkat kepentingan item-item yang dianalisis dengan tingkat kepuasan mahasiswa terhadap item tersebut. Interpretasi grafik IPA dibagi menjadi empat buah kuadran,yaitu:

i) Kuadran I memiliki atribut dengan tingkat kepuasan rendah dan kepentingan tinggi sehingga perlu ditingkatkan kinerjanya.

ii) Kuadran II memiliki atribut dengan tingkat kepuasan tinggi dan kepentingan tinggi sehingga harus dipertahankan.

iii) Kuadran III memiliki atribut dengan tingkat kepuasan rendah dan 
kepentingan rendah memberikan pengaruh yang kecil.

iv) Kuadran IV memiliki atribut dengan tingkat kepuasan tinggi dan kepentingan rendah dirasakan pengguna terlalu berlebihan.

c) Analisis Biplot.

Analisis biplot untuk menyajikan datadata yang ada di tabel ringkasan berdimensi dua dengan melihat karakteristik pengguna GT dengan atribut lima aspek yang dinilai pada layanan. Objek yang dimaksud dalam analisis adalah pengguna GT,sedangkan peubahnya adalah nilai rata-rata tingkat kepuasan kelima aspek yang dinilai. Informasi yang diperoleh dari analisis biplot ini kemiripan tingkat kepuasan, keragaman aspek, korelasi antar peubah, serta nilai aspek berdasar posisi relatif (Sumarjaya and Srinadi (2016)).

d) Analisis Korespondensi Sederhana. Analisis korespondensi dapat memproyeksikan baris-baris dan kolom-kolom dari matriks data sebagai titik-titik ke dalam sebuah grafik berdimensi rendah dalam sebuah jarak Euclid. Analisis korespondensi seringkali digunakan untuk menetapkan kategori-kategori yang mirip dalam satu peubah, sehingga kategori-kategori tersebut dapat digabungkan menjadi satu Mattjik and Sumertajaya (2011). Analisis korespondensi digunakan untuk melihat profil hubungan antara strata (fakultas) dengan kecenderungan jenis GT yang digunakan.

\section{HASIL DAN PEMBAHASAN}

\section{A. Uji Validitas dan Reliabilitas Kuesioner}

Uji validitas kuesioner dilakukan dengan menggunakan korelasi bivariat Pearson (Putra et al. (2014)). Nilai korelasi yang diperoleh selanjutnya dibandingkan dengan nilai r-tabel. Nilai r-tabel pada saat $\mathrm{n}=30$ dan alpha 5\% adalah sebesar 0.361 . Hal ini berarti bahwa kuesioner telah valid pada alpha 5\%. Croanbach alpha digunakan untuk menguji kekonsistenan kuesioner. Kuesioner dikatakan konsisten (reliabel) jika nilai alpha lebih besar dari 0.6. Hasil yang diperoleh menunjukkan bahwa nilai $\mathrm{p}$ untuk semua pertanyaan lebih besar dari 0.6, dengan demikian kuesioner sudah reliabel.

\section{B. Statistika Deskriptif}

\section{Gambaran Umum Responden}

Jumlah responden yang diperoleh berdasarkan hasil perhitungan awal penelitian adalah sebanyak 389 , kemudian setelah dilakukan survei banyaknya responden yang diperoleh sebanyak 259. Jumlah responden yang diperoleh tidak mencapai target karena banyaknya responden nonrespon. Pelaksanaan Survei ini dilakukan secara online dan offline. Hasil yang diperoleh dengan melibatkan 193 responden berasal dari survei online dan survei offline sebanyak 66 responden . Banyaknya responden yang diperoleh sudah mewakili setiap strata dalam penelitian ini. Jumlah responden paling banyak berasal dari FMIPA (G), sedangkan yang paling sedikit berasal dari FKH (B), FAHUTAN (E) dan FEMA (I). Perbandingan antara jumlah perolehan responden dan target responden disajikan pada Gambar 2.

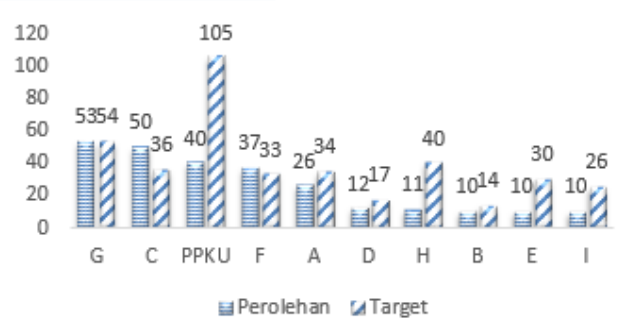

Gambar 2. Perbandingan jumlah target dan perolehan responden

Jumlah pengguna masing-masing mode transportasi seminggu terakhir yang pernah digunakan responden tersaji pada Gambar 3. Mayoritas responden sering berjalan kaki. Mode transportasi GT yang banyak digunakan oleh responden adalah 
bus yaitu sebanyak 104 responden, selanjutnya mobil listrik sebanyak 43 responden, sepeda sebanyak 6 responden. Mode transportasi GT ojek listrik tidak pernah digunakan oleh seluruh responden. Responden juga menggunakan mode transportasi non GT seperti ojek kampus sebanyak 83 responden, motor pribadi sebanyak 129 responden dan 21 mahasiswa yang menggunakan mode transportasi non GT lainnya. Mode transportasi non GT lain yang dimaksud adalah mobil pribadi, angkot, kendaraan umum, dan boncengan dengan teman.

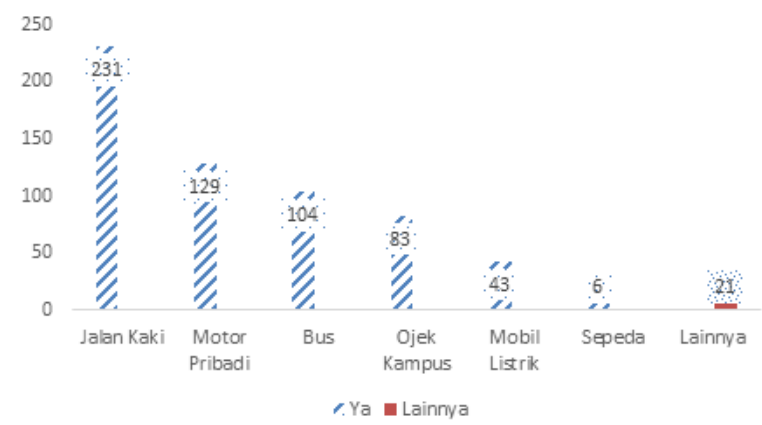

Gambar 3. Jumlah penggunaan mode transportasi seminggu terakhir

Frekuensi pengguna mode transportasi seminggu terakhir oleh responden disajikan dalam Gambar 4. Mode transportasi yang paling jarang digunakan adalah ojek listrik. Hal ini dikarenakan hampir seluruh responden tidak mengetahui keberadaannya. Mode transportasi yang paling sering digunakan yaitu bus.

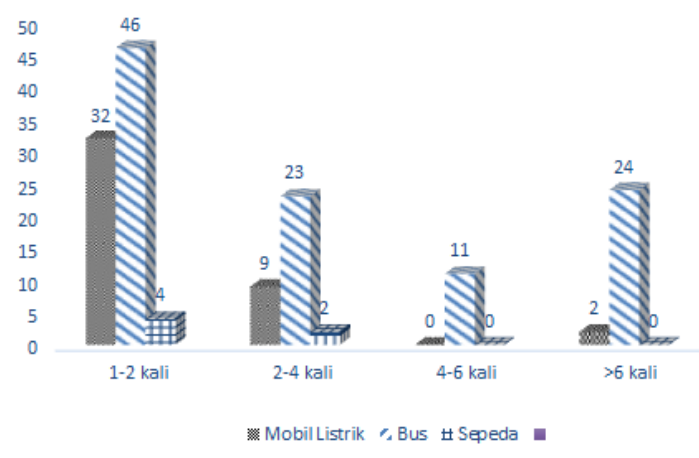

Gambar 4. Frekuensi penggunaan mode transportasi seminggu terakhir

\section{Analisis IPA-CSI}

Hasil yang diperoleh adalah nilai CSI sebesar 2.96 dengan persentase CSI $74 \%$ dengan kata lain pengguna sudah puas terhadap pelayanan yang diterimanya. Nilai CSI yang diperoleh untuk masing-masing mode transportasi GT adalah 2.91 untuk mobil listrik, 3.05 untuk bus, dan 2.94 untuk sepeda. Masing-masing mode transportasi GT memiliki persentase $73 \%$ untuk mobil listrik, $76 \%$ untuk bus, dan $73 \%$ untuk sepeda. Hasil analisis diagram IPA secara keseluruhan GT dimuat pada Gambar 6. Aspek emphaty dan assurance berada dikuadran I, sehingga wilayah ini atributatributnya harus ditingkatkan. Aspek responsiveness dan tangible berada dikuadran II, sehingga wilayah ini atribut-atributnya harus dipertahankan. Aspek reliability berada dikuadran III, sehingga wilayah ini atribut-atributnya memberikan pengaruh yang kecil terhadap pengguna.

Hasil analisis diagram IPA mobil listrik dimuat pada Gambar 9. Sumbu horizontal menunjukkan tingkat kepuasan sedangkan vertikal menunjukkan tingkat kepentingan. Kuadran I memiliki aspek kepuasan yaituempathydanreliability, wilayah ini yang memuat atribut-atribut yang memiliki tingkat kepentingan relatif tinggi tetapi kenyataannya belum sesuai dengan harapan pengguna. Oleh karena itu aspekemphatyharus segera ditingkatkan kinerjanya. Kuadran II memiliki aspek kepuasan yaituassurance,dan tangibles, wilayah yang aspekaspek ini memiliki tingkat kepentingan relatif tinggi dengan tingkat kepuasan yang relatif tinggi, sehingga harus tetap dipertahankan karena semua atribut ini menjadikan fasilitas tersebut unggul di mata pengguna. Kuadran III memiliki aspek kepuasan yaituresponsiveness.Aspek ini memiliki tingkat kepentingan yang relatif rendah dan tingkat kepuasan yang relatif rendah. Atribut yang termasuk dalam kuadran ini memberikan pengaruh sangat kecil terhadap manfaat yang dirasakan oleh pengguna.

Hasil analisis diagram IPA bus yang dimuat pada Gambar 7. Aspek tangibles berada di kuadran II, wilayah yang memuat atribut ini memiliki tingkat kepentingan relatif tinggi dengan tingkat 


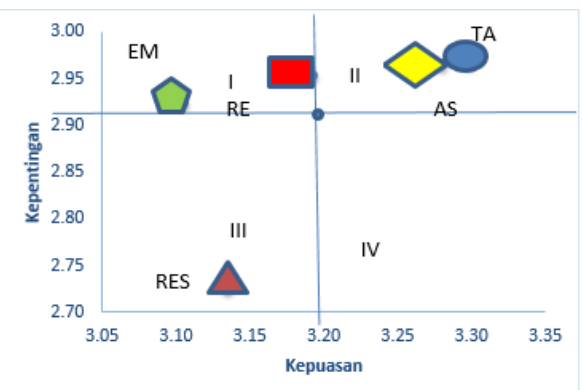

Gambar 5. Plot kepentingan vs kepuasan mahasiswa pengguna mobil listrik

kepuasan yang relatif tinggi. Oleh karena itu Aspek tangibles dianggap sebagai faktor penunjang bagi kepuasan pengguna sehingga harus tetap dipertahankan karena semua atribut ini menjadikan fasilitas tersebut unggul di mata pengguna. Aspek reliability dan emphaty berada di kuadran III , wilayah yang memuat atribut-atribut dengan tingkat kepentingan yang relatif rendah dan kenyataan kinerjanya tidak terlalu istimewa dengan tingkat kepuasan yang relatif rendah. Aspek reliability dan emphaty memberikan pengaruh sangat kecil terhadap manfaat yang dirasakan oleh pengguna. Aspek responsiveness dan assurance berada di kuadran IV, wilayah ini memuat atribut-atribut dengan tingkat kepentingan yang relatif rendah dan dirasakan oleh pengguna terlalu berlebihan dengan tingkat kepuasan yang relatif tinggi. Biaya yang digunakan untuk menunjang atribut yang termasuk dalam kuadran ini, dapat dikurangi agar dapat menghemat biaya pengeluaran.

Aspekassuranceberada di kuadran I, sehingga wilayah ini atribut-atribut yang harus segera ditingkatkan kinerjanya karena belum sesuai dengan harapan pengguna. Aspekresponsivenessberada di kuadran II, wilayah yang memuat atribut ini memiliki tingkat kepentingan relatif tinggi dengan tingkat kepuasan yang relatif tinggi. Oleh karena itu aspekresponsivenessdianggap sebagai faktor penunjang bagi kepuasan pengguna sehingga harus tetap dipertahankan karena semua atribut ini menjadikan fasilitas tersebut unggul di mata pengguna. Aspekreliabilitydantangiblesberada di kuadran III, sehingga kuadran ini memiliki atribut

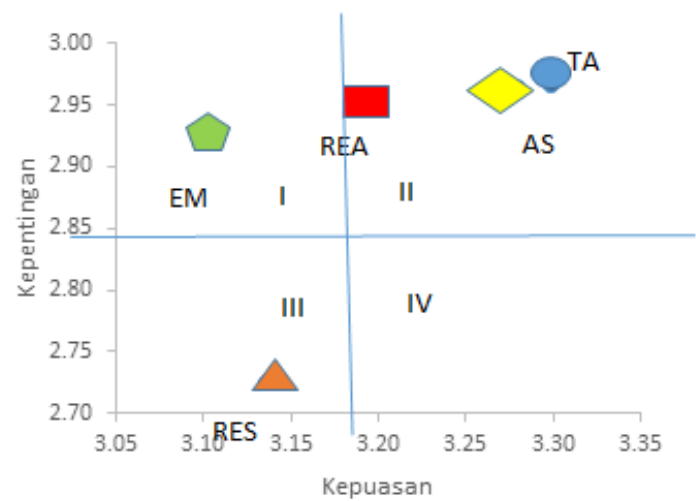

Gambar 6. Plot kepentingan vs kepuasan mahasiswa pengguna bus

yang memberikan pengaruh sangat kecil terhadap manfaat yang dirasakan oleh pengguna. Aspekemphatyberada di kuadran IV, wilayah ini memuat atribut-atribut dengan tingkat kepentingan yang relatif rendah dan dirasakan oleh pengguna terlalu berlebihan dengan tingkat kepuasan yang relatif tinggi. Biaya yang digunakan untuk menunjang atribut yang termasuk dalam kuadran ini, dapat dikurangi agar dapat menghemat biaya pengeluaran.

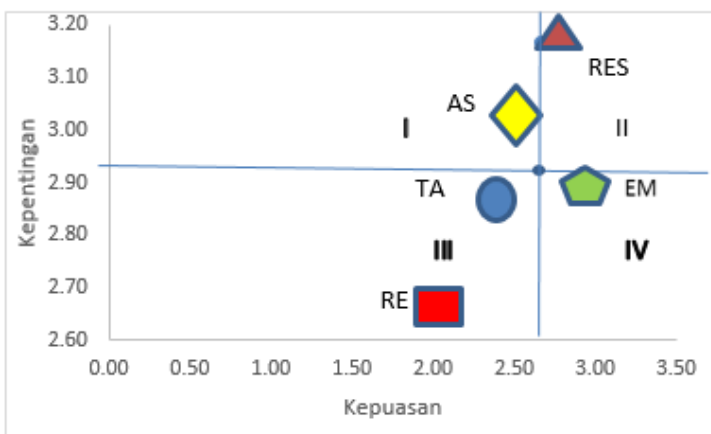

Gambar 7. Plot kepentingan vs kepuasan mahasiswa pengguna sepeda

\section{Analisis Biplot}

Hasil analisis biplot disajikan pada Gambar 9. Sebesar $99.9 \%$ keragaman kepuasan mahasiswa mampu dijelaskan oleh biplot. Masing-masing nilai komponen pertama sebesar $99.8 \%$ dan komponen kedua sebesar $0.1 \%$. Hasil analisis biplot menunjukkan kedekatan karakteristik fakultas dengan 
5 dimensi kepuasan pelanggan, nilai relatif tiap aspek kepuasan pada layanan GT tiap pengguna mode transportasi tersebut, keragaman data aspek kepuasan, dan nilai korelasi antar aspek. Gambar 9 memperlihatkan bahwa semua vektor peubah aspek kepuasan mempunyai panjang vektor yang relatif sama. Hal ini menunjukkan keragaman kepuasan dari setiap aspek cenderung sama. Hasil analsis biplot memperlihatkan tidak ada fakultas yang saling berdekatan, sehingga tidak memiliki karakteristik relatif yang sama. FAPET (D) dan FEMA (H) unggul dalam aspek tangibles dan reliability karena posisi relatif, karena fakultas tersebut berada diatas dan searah dengan kedua vektor peubah aspek tersebut. FAPERTA (A), FPIK (C), FMIPA (G) dan FEMA (I) berhubungan negatif dengan FAPET (D) dan FEM (H). FAHUTAN (E), FATETA (F), dan program pendidikan kompotensi umum (PPKU) unggul dalam aspek assurance, emphaty dan responsiveness karena posisi relatif fakultas berada searah dan berada ditengah vektor peubah aspek tersebut. FKH (B) berhubungan negatif dengan FAHUTAN (E), FATETA (F), dan program pendidikan kompotensi umum (PPKU).

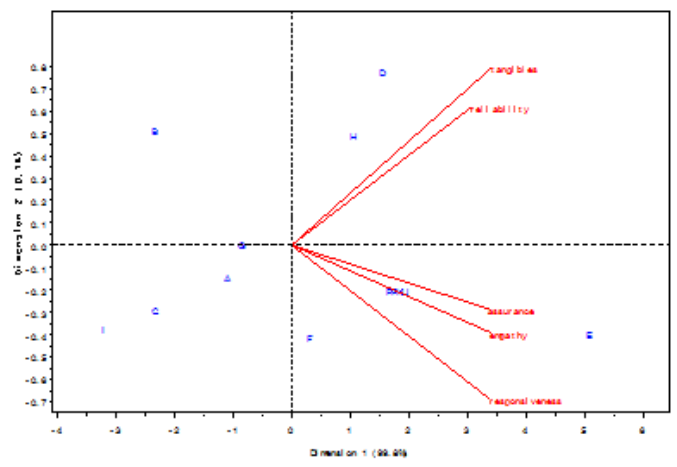

Gambar 8. Biplot antara fakultas dengan rata-rata aspek kepuasan

\section{E. Analisis Korespondensi Sederhana}

Hasil korespondensi menggambarkan berapa persen kemampuan plot korespondensi memberikan informasi dari data. Hasil yang diperoleh bahwa dengan menggunakan 2 dimensi pertama, mampu menerangkan data asal sebesar $77.05 \%$. Informasi yang diberikan sudah cukup bagus.
Gambar 10. memperlihatkan bahwa fakultas yang sering menggunakan mobil listrik yaitu FKH (B), FAPET (D), FAHUTAN (E), dan program pendidikan kompotensi umum (PPKU), kemudian fakultas yang sering menggunakan bus yaitu FAPERTA (A), FPIK (C), FATETA (F),FMIPA (G) dan FEMA (I), sedangkan fakultas yang menggunakan sepeda yaitu FEM (H). Hal ini dapat kita lihat berdasarkan tabel kontingensi strata dengan kecenderungan GT yang dipilih. Hasilnya mobil listrik menunjukkan responden yang paling banyak menggunakan yaitu FATETA $(\mathrm{F})$ sebanyak 10, sedangkan yang paling sedikit yaitu FAPERTA (A), FKH (B) dan FAPET (D) sebanyak 3. Bus menunjukkan responden yang paling banyak menggunakan yaitu fakultas FATETA (A) sebanyak 10, FMIPA (G) sebanyak 17, sedangkan yang paling sedikit yaitu FEM (H).Sepeda menunjukkan responden yang menggunakan yaitu FPIK (C) sebanyak 2, FEMA (I) dan FEM (H) sebanyak 1 .

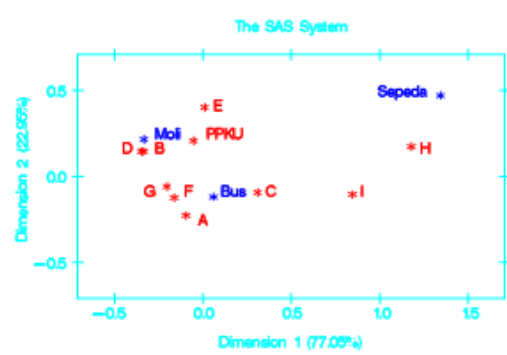

Gambar 9. Korespondensi antara fakultas dengan jenis GT

\section{F. Kritik/saran untuk Green Transportation}

Ringkasan hasil kritik/saan dari pengguna GT ditunjukkan pada Gambar 11. Sebanyak 57 responden mengeluhkan tentang waktu beroperasinya GT yang kurang terjadwal dan waktu yang lama. Hal ini disebabkan mahasiswa merasa jadwal yang ada belum melewati jalur transportasi secara menyeluruh. Hasil lainnya adalah sebanyak 51 responden menilai masih kurangnya armada GT seperti bus dan mobil listrik beroperasi sedangkan pengguna GT banyak sehingga perlu ditambah lagi. Selain itu sebanyak 39 responden mengharapkan peraturan GT agar lebih tegas 
dalam penerapan kebijakan GT seperti pembatasan kendaraan yang masuk dilingkungan IPB dan sanksi yang perlu dilakukan agar kendaraan masuk tertib. Fasilitas yang ditingkatkan lagi agar memberikan kepuasan dan kenyamanan bagi pengguna sebanyak 33 dengan meningkatkan kualitas layanan GT dan memperhatikan setiap rute pengguna GT. Salah satu kendala penerapan GT yaitu banyaknya ojek kampus, kendaraan pribadi dilingkungan kampus, waktu yang belum terjadwal dengan baik. Oleh karena itu diharapkan IPB bisa membuat sistem lebih baik, konsisten, dan mode transportasi GT yang selalu ada.

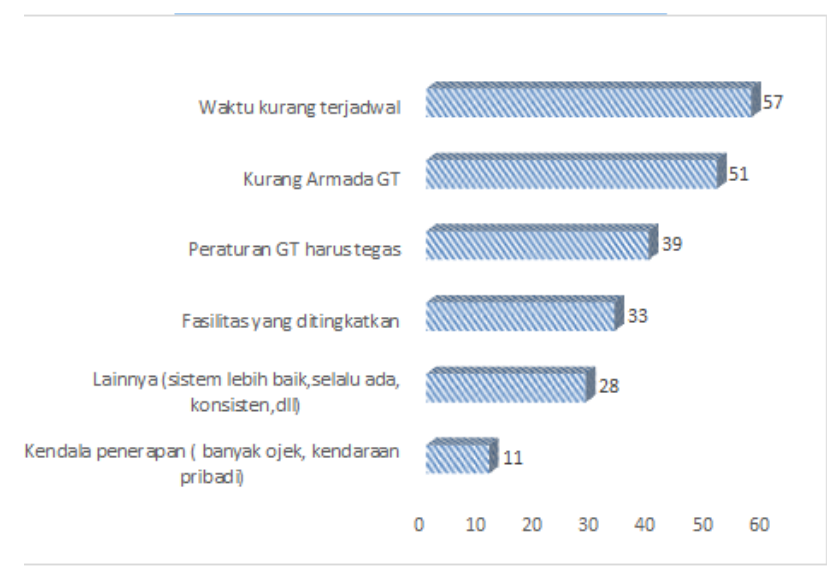

Gambar 10. Kritik/saran untuk GT

\section{SIMPULAN}

Pengguna GT sudah puas terhadap layanan GT yang ada di lingkungan kampus IPB Dramaga, hal ini ditunjukkan dengan nilai CSI yang diperoleh sebesar 2.96 dan persentase CSI sebesar 74\%.Aspekemphaty dan reliability pelayana mode transportasi mobil listrik perlu ditingkatkan sedangkan aspek yang perlu ditingkatkan pada mode transportasi sepeda adalah aspekassurance.Aspekaspek yang lain sudah dinilai baik oleh mahasiswa IPB. Hasil analisis biplot menunjukkan keragaman kepuasan dari ke-5 aspek reliability, emphaty, tangibles, assurance, dan responsiveness)adalah sama. Mode transportasi GT yang sering digunakan adalah bus lalu diikuti oleh mobil listrik dan sepeda sedangkan ojek listrik tidak pernah digunakan karena tidak diketahui mahasiswa IPB. Ma- hasiswa FKH, FAPET, FAHUTAN dan PPKU sering menggunakan mode transportasi mobil listrik. Mode transportasi bus sering digunakan oleh mahasiswa FAPERTA, FPIK, FATETA, dan FMIPA. Mode transportasi sepeda tidak dapat dicirikan pada Fakultas manapun dikarenakan sedikitnya responden yang menggunakannya.

\section{DAFTAR PUstaka}

Mattjik, K. and I. Sumertajaya (2011). Sidik Peubah Ganda dengan Menggunakan SAS. Bogor(ID: Institut Pertanian Bogor.

Putra, Z., M. Sholeh, and N. Widyastuti (2014). Analisis kualitas layanan website btkp-diy menggunakan metode webqual 4.0. Jurnal JARKOM 1(2), ISSN:2338-6312.

Scheaffer, R., 1. W. Mendenhal, R. Ott, and K. Gerow (2012). Elementary Survey Sampling. Boston(US): Brooks/cole.

Siregar (2013). Metode Penelitian : Dilengkapi dengan Perbandingan Perhitungan Manual dan SPSS. Jakarta(ID: PT Gramedia Pustaka Utama.

Sumarjaya, I. and I. Srinadi (2016). Analisis biplot untuk pemetaan posisi dan karakteristik usaha parawisata di provinsi bali. Jurnal Matematika 6(1), 34-45. 